\title{
A CRISE DA DEMOCRACIA LIBERAL E A EMERGÊNCIA DO POPULISMO DE DIREITA NO SÉCULO XXI
}

THE CRISIS OF LIBERAL DEMOCRACY AND THE EMERGENCY OF RIGHT-WING POPULISM IN THE 21ST CENTURY

Mayra Goulart

Professora no Departamento de Ciência Política da Universidade Federal do Rio de Janeiro (UFRJ) e no Programa de Pós-graduação em Ciência Sociais da Universidade Federal Rural do Rio de Janeiro (UFRRJ). Doutora e mestra em Ciência Política pelo Instituto de Estudos Sociais e Políticos da Universidade do Estado do Rio de Janeiro (IESP/UERJ).

\section{Theófilo Rodrigues}

Pesquisador com pós-doutorado no Programa de Pós-graduação em Ciências Sociais da Universidade do Estado do Rio de Janeiro (UERJ). Doutor em Ciências Sociais pela Pontifícia Universidade Católica do Rio de Janeiro (PUC-Rio) e mestre em Ciência Política pela Universidade Federal Fluminense (UFF). 


\section{RESUMO}

Não parece haver muitas dúvidas de que neste início de século XXI a democracia liberal tenha enfrentado certas crises. O Brexit, no Reino Unido, e as eleições de Donald Trump, nos Estados Unidos; Jair Bolsonaro, no Brasil; e Viktor Orbán, na Hungria, parecem ser casos sintomáticos desse processo. O presente artigo analisa as bases epistêmicas da democracia liberal, bem como as razões que possibilitaram suas recentes crises. O artigo está estruturado em quatro seções. A primeira discute o pluralismo no contexto da democracia liberal nas obras de Rawls e Habermas. A segunda seção traz a leitura crítica de Laclau e Mouffe acerca do pluralismo liberal e acrescenta a perspectiva populista no debate. A terceira seção trata das bases do consenso e da hegemonia da democracia liberal. Por fim, a última seção apresenta uma interpretação da crise da hegemonia liberal e da alternativa populista que emerge, em particular, o populismo de direita.

Palavras-chave: democracia liberal; pluralismo; populismo.

\section{ABSTRACT}

At the beginning of the 2Ist century, liberal democracy faced some crises. Brexit in the UK and the elections of Donald Trump in the US, Jair Bolsonaro in Brazil and Viktor Orbán in Hungary seem to be symptomatic of this process. This article seeks to understand the epistemic bases of liberal democracy, as well as the reasons that made its recent crises possible. The article is divided into four sections. The first discusses pluralism in the context of liberal democracy in Rawls and Habermas. The second section brings Laclau and Mouffe's critical reading of liberal pluralism and adds a populist perspective to the debate. The third section deals with the bases of consensus and hegemony of liberal democracy. Finally, the fourth and last section presents an interpretation of the crisis of liberal hegemony and the populist alternative that emerges, in particular right-wing populism.

Keywords: liberal democracy; pluralism; populism. 


\section{Introdução}

O dia 6 de janeiro de 202I certamente entrou para a história. Naquela tarde da primeira quarta-feira do ano, o mundo inteiro assistiu atônito às imagens de centenas de manifestantes, com trajes que remetiam ao supremacismo branco, invadindo o Capitólio, a sede do Congresso dos Estados Unidos. Naquele dia, o Congresso estava em sessão, conduzindo a contagem de votos do Colégio Eleitoral da eleição de 2020. No lado de fora do prédio, milhares de manifestantes protestavam e acusavam a eleição presidencial de ter sido fraudada. E o pior: com o apoio do próprio presidente do país, Donald Trump, que não reconheceu o resultado eleitoral e incentivou seus seguidores a atacarem o parlamento. Não demorou muito para que uma parte da multidão superasse as forças policiais, derrubasse as grades e invadisse os salões de um dos principais prédios do governo estadunidense. Dentro do prédio, uma invasora acabou sendo baleada e morta por um policial. A cena trágica, no entanto, acabou sendo invisibilizada diante da mensagem maior do que ocorreu naquele dia: a maior democracia liberal do mundo já não era mais um consenso nem mesmo para seus cidadãos.

Não parece haver muitas dúvidas de que nesse início de século XXI a democracia liberal tenha enfrentado certas crises. O Brexit, no Reino Unido, e as eleições de Donald Trump, nos Estados Unidos; Jair Bolsonaro, no Brasil; e Viktor Orbán, na Hungria, parecem ser casos sintomáticos desse processo. Claro, a crise da democracia liberal não significa sua morte. Trump foi derrotado e Joe Biden, um típico representante da democracia liberal, o substituiu. Mas ainda assim não é trivial lembrar que o presidente da principal democracia liberal do mundo não reconheceu um resultado eleitoral e que uma parcela de seus seguidores invadiu violentamente a sede do Congresso.

No Brasil, o que Bolsonaro faz com seus seguidores não é muito diferente do que Trump fez nos Estados Unidos. Com uma agenda politicamente autoritária, socialmente conservadora e economicamente neoliberal, Bolsonaro também articulou um populismo de direita contra a democracia liberal (SILVA; RODRIGUES, 202I). O discurso bolsonarista de que a eleição de 2022 poderá não ser reconhecida se não houver o chamado "voto impresso" faz parte dessa narrativa de desconstrução das bases da democracia liberal; bem como os ataques contra os ministros do Supremo Tribunal Federal (STF), que partem do próprio presidente da república. No caso brasileiro, o STF reagiu e acolheu investigações contra líderes bolsonaristas que atuaram na esfera pública com discursos de deslegitimação das instituições políticas. Mas até onde irá essa escalada?

Antes de Bolsonaro e Trump, o primeiro-ministro da Hungria, Viktor Orbán, já havia declarado, em 20I4, que o objetivo de seu governo seria construir um "Estado iliberal". Pouco a pouco, Orbán transformou os canais de televisão estatais em veículos de propaganda, censurou a imprensa e controlou o tribunal constitucional do país (MOUNK, 2OI9). 
Trump, Bolsonaro e Orbán são representantes daquilo que a teoria política convencionou chamar de um populismo de direita (MOUFFE, 20I8). A semelhança entre eles não reside apenas no ataque frontal às tradicionais instituições políticas da democracia liberal. Os três articulam programas semelhantes, com base no casamento de uma agenda reacionária nos valores e neoliberal na economia. Essa é a base do populismo de direita que expressam.

O presente artigo analisa as bases epistêmicas da democracia liberal, bem como as razões que possibilitaram suas recentes crises. O artigo está estruturado em quatro seções. A primeira discute o pluralismo no contexto da democracia liberal nas obras de Rawls e Habermas. A segunda seção traz a leitura crítica de Laclau e Mouffe acerca do pluralismo liberal e acrescenta a perspectiva populista no debate. A terceira seção trata das bases do consenso e da hegemonia da democracia liberal. Por fim, a última seção apresenta uma interpretação da crise da hegemonia liberal e da alternativa populista que emerge, em particular, o populismo de direita.

\section{O fato do pluralismo e a objeção da identidade dividida}

O mundo não é uma unidade política, e sim um pluriversum político, afirma Carl Schmitt no título de um dos capítulos de O conceito do político (2008). Esse diagnóstico, que desafia liberais e seus críticos, resulta no desafio de criar parâmetros jurídico-políticos comuns capazes de oferecer algum liame a sociedades complexas, constituídas por diferentes grupos e identidades coletivas. John Rawls é um desses liberais que toma para si o desafio de lidar com o que denominou como fato do pluralismo ou "fact of reasonable pluralism" (RAWLS, 200I, p. 32), e também estabelecer os limites para que ele não se traduza em uma ameaça às conquistas civilizatórias de um processo de lutas políticas, iniciado pelas revoluções burguesas, que resultou na fixação de critérios para a vida coletiva: a preservação dos direitos individuais e a ideia de soberania popular (RAWLS, 2OII).

De acordo com Rawls, o problema do liberalismo político pode ser formulado da seguinte maneira: "como é possível que possa existir ao longo do tempo uma sociedade estável e justa de cidadãos livres e iguais profundamente divididos por doutrinas religiosas, filosóficas e morais razoáveis, embora incompatíveis entre si?" (RAWLS, 20II, p. XIX). Para o autor, o fato do pluralismo significa que pessoas razoáveis podem discordar acerca de como deveriam viver, porém concordariam com os princípios constitucionais elementares para a preservação desses critérios civilizacionais, que passam a ser entendidos como neutros em relação às diferentes concepções de "bem" dispostas na sociedade. Essa ideia de neutralidade, ainda que entendida como resultado de um processo histórico, após o que chamamos de guinada contextualista no 
pensamento rawlseano, é criticada por outros liberais da mesma família, como apresenta Jürgen Habermas ao se colocar no debate (RAWLS; HABERMAS, I998).

O problema levantado pelos habermasianos e outros críticos que a ele se uniram posteriormente é que esses argumentos supostamente neutros são mais próximos de algumas concepções de bem particulares - laicas - e menos próximas de outras - religiosas, por exemplo. Com isso, cidadãos religiosos e demais portadores de concepções de bem não laicas carregariam um fardo maior que os demais. Para validar sua participação no debate público, a eles seria exigida uma dinâmica de reflexividade ou abertura identitária mais profunda, na medida em que precisariam se despir de suas convicções mais profundas sobre o bem e o justo no momento em que fossem se posicionar sobre questões políticas. Isso porque tais convicções, por serem estruturadas com base em argumentos religiosos, seriam incompatíveis com os princípios que estruturam a esfera pública liberal. Essa problemática ficou conhecida como "a objeção da identidade dividida" (YATES, 2007, p. 88I), e resume as críticas a uma concepção de esfera pública que impõe uma obrigação injusta a alguns cidadãos de se dividirem em "eus" não públicos e públicos.

A objeção da identidade dividida é referida como "dano dignitário" por Perry (1988) e como a distinção crença-ação em Murphy (1988). Ambos os autores ressaltam que as condições que Rawls estabelece para o engajamento no debate público são injustas com aqueles que portam concepções religiosas de bem, tendo em vista seu caráter estruturante que orienta não apenas as decisões privadas dos fiéis, mas também seus posicionamentos acerca das questões político-jurídicas. Nos termos rawlseanos a divisão se dá entre o que seria uma concepção política ou neutra de justiça e outras orientadas por doutrinas compreensivas ou abrangentes o suficiente para permitirem essa abertura, sendo esse o critério para validar ou proscrever determinadas concepções de bem (RAWLS, 2OII).

Para Rawls, uma sociedade liberal precisa aceitar o fato do pluralismo de identidades e concepções de bem, mas também limitá-lo àquelas capazes de operar essa divisão, isto é, capazes de atuar na esfera pública em termos laicos, a estas o autor chama de doutrinas compreensivas (comprehensive doctrines). Tais doutrinas, embora diferentes, convergiriam nos critérios valorativos determinantes para a vida pública, estruturados com base nas ideias de soberania popular e direitos humanos, dando origem ao que Rawls (200I) denomina consenso sobreposto (overlapping consensus). Doutrinas compreensivas são, portanto, aquelas portadas por cidadãos razoáveis e que terão o privilégio de poder encontrar pontos de continuidade entre suas identidades morais pública e privada. Os demais, aqueles que orientam a vida por doutrinas/concepções de bem distintas desses parâmetros de razoabilidade precisarão se submeter a esse processo de cisão identitária caso queiram participar do debate público. Religiões, portanto, precisariam se abrir a processos reflexivos 
e dialógicos nos quais há discordância sobre a ideia de bem, o que ignoraria limitações epistêmicas para esse tipo de abertura por parte de alguns pontos de vista religiosos, sobretudo aqueles de caráter conservador, que por este motivo teriam mais dificuldade de participar do debate público do que seus concidadãos liberais (GREENAWALT, 1993).

Rejeitando a concepção substantiva de neutralidade rawlseana e reconhecendo que juízos político-legislativos são necessariamente contaminados por visões de mundo particular - concepções de bem -, Habermas defende um critério procedural de legitimidade, apresentado sob a fórmula de um princípio racional. Desenvolvida entre direito e democracia, facticidade e validade, essa fórmula diz respeito à adesão de todos os possíveis envolvidos às decisões tomadas em um processo deliberativo (HABERMAS, 2003). Habermas, por sua vez, seria mais equânime do que Rawls ao impor exigências iguais a cidadãos religiosos e não religiosos sendo essa exigência relacionada a uma abertura cognitiva, "cognitive openness" (YATES, 2007, p. 887). A ideia é que esse seja um fardo igualmente compartilhado entre todos os cidadãos, uma vez que os não religiosos precisam estar abertos aos argumentos religiosos e, inclusive, à possibilidade de que as instituições públicas possam ser revestidas de linguagem religiosa (YATES, 2007). Por outro lado, cidadãos religiosos precisariam deixar de lado argumentos que pressuponham a verdade de suas crenças em detrimento de outras. $\mathrm{O}$ que de certo modo não responde às críticas que enfatizam os condicionantes epistêmicos do pensamento religioso que dificultariam essa operação (ESTLUND, I998; GARDBAUM, 1996; RAZ, I990).

Em suma, para Rawls (2OII), na esfera pública, todos os posicionamentos devem ser justificados com base em uma argumentação racional, enquanto para Habermas, deve haver espaços informais de deliberação nos quais todo tipo de argumentação é permitido. Conforme desenvolvida em fé e saber, a constituição de um regime liberal-democrático não é compatível com a exclusão apriorística de nenhum ponto de vista, pois os princípios de legitimidade que orientam esse tipo de ordem constitucional não emergiriam de um ponto de vista neutro, mas de um debate imerso em valores culturais particulares e mutáveis (HABERMAS, 20I3). O argumento é valioso: o que se entende por democracia liberal é produto de um processo reflexivo dialógico que envolve diferentes concepções de bem, inclusive as religiosas.

\section{Populismo, hegemonia e afetos: limites do liberalismo e sua incapacidade de lidar com os desafios da conjuntura}

É uma alegoria a ideia de um consenso produzido espontaneamente de uma deliberação envolvendo, em condições de igual liberdade de participação, membros de diferentes grupos sociais, cada qual com sua identidade e concepção de bem, todas elas abertas a processos 
reflexivos acerca de seus postulados e nas quais a única força envolvida é a do melhor argumento. Nenhum habermasiano concebe essa ideia como descrição cabível para dinâmicas reais, mas como um horizonte normativo capaz de orientá-la. No entanto, como alertam os herdeiros mais radicais da teoria crítica, a normalidade da democracia liberal é criada por um consenso fictício de que, por deliberação racional, as necessidades e as demandas de todas as partes e pessoas afetadas poderiam ser gerenciadas e atendidas.

Levando a sério tanto a postulação original como suas críticas, o que se discute aqui são as implicações dessa normatividade, na qual as ideias de igualdade e liberdade são inoculadas de seu potencial contra-hegemônico. Ao ser enquadradas como condições para o estabelecimento de consensos necessários para um ordenamento jurídico-político, essas formulações ignoram as relações de poder que as originaram. Desse modo, como argumentam Ernesto Laclau e Chantal Mouffe (2015) no seminal Hegemonia e estratégia socialista: por uma política democrática radical, todo consenso, toda ordem, toda ideia de razoabilidade, é produto de uma relação de poder que inviabiliza e silencia opiniões contrastantes. Incluindo a contribuição de Jacques Rancière (1999) nessa formulação, mecanismos de marginalização e hierarquização atuam na produção desse consenso, resultando em binarismos como dentro/fora, nós/eles e centro/periferia. Todo consenso ou verdade é uma decisão política de excluir determinados modos de vida em prol da normalização de outros (MOUFFE, 2005b). Em suma, a função da distinção entre "razoável" e "irracional" é delinear uma fronteira entre as doutrinas que aceitam os princípios liberais e aqueles que se opõem a eles. $O$ debate sobre os limites do pluralismo se reduziria então ao confronto entre um pluralismo permissível de concepções religiosas, morais ou filosóficas contanto que essas visões possam ser relegadas à esfera do privado e satisfaçam os princípios liberais - e o que seria um pluralismo inaceitável porque colocaria em risco o domínio dos princípios liberais na esfera pública (MOUFFE, 2000).

Marion Young (2006) define opinião como princípio, valor e prioridade assumidos por uma pessoa na fundamentação de seus juízos privados e públicos. Essas opiniões, seguindo o argumento da autora, podem se basear em sistemas de conhecimento disciplinares e laicos como a economia e a ciência - ou em motivações religiosas. Hegemonia, por sua vez, é um conceito que desafia a relação entre consenso e opiniões, na medida em que diz respeito à conformação de um aparato institucional responsável por reverberar opiniões, ampliando sua disseminação, construindo consensos e, por fim, recobrindo-as com o manto da verdade. Escamoteando sua origem ou afinidade com um sistema de crenças, a hegemonia estabiliza e confere legitimidade a determinada relação de força entre seus portadores e os demais (ALVES, 20Io). No tocante ao debate estabelecido, acerca dos limites do pluralismo, o conceito chama a atenção para o caráter defensivo dessa reflexão, forjada com o intuito de 
proteger a hegemonia do pensamento liberal - e dos segmentos com ele identificados e por ele beneficiados - diante de ameaças epistêmicas, sociais e políticas.

Em uma contribuição mais atual, Mouffe (2000) desenvolve o argumento em termos particularmente caros ao debate aqui empreendido, alertando para as ideias de razoabilidade, racionalidade e universalidade inerentes à formulação liberal e no quanto ela torna vulnerável a contestações promovida por concepções epistêmicas mais capazes de lidar com o aspecto emocional e com os particularismos, inelutáveis a qualquer configuração identitária baseada em uma ideia pública ou privada de bem. Emoções, sentimentos e afetos foram proscritos das conceituações liberais de esfera pública, sendo limitados à esfera privada supostamente protegida da ação do Estado e, portanto, alheia às decisões e aos debates políticos. É apenas nesse arranjo que faz sentido a pretensão de que os processos deliberativos devem ser regidos apenas pela razoabilidade e pela persuasão do melhor argumento - mesmo que essa crença seja minada pela afetividade de toda política na práxis (MOUFFE, 200o). Teóricos da democracia radical reconhecem o valor do liberalismo e reforçam a importância de defendê-lo diante do recrudescimento do autoritarismo. Porém, essa defesa passa pela radicalização de seus princípios constitutivos: igualdade, liberdade e pluralismo (LACLAU; MOUFFE, 2015). Essa defesa não pode fechar os olhos para os problemas associados aos conceitos de esfera pública, racionalidade e razoabilidade, assim como à crença dos procedimentos deliberativos de promoverem convergências e consensos espontâneos entre visões de mundo. Aceitar o fato do pluralismo, nessa acepção mais radical, é compreender que: (i) o dissenso entre as concepções de bem é inerradicável e impossível de ser subsumido a um acordo formal acerca de princípios básicos (overlapping consensus), posto que é acerca desses mesmos princípios básicos - como as ideias de igualdade e liberdade, por exemplo - que se instauram muitas das divergências (MOUFFE, 2005b); (ii) algumas posições serão impossíveis de serem traduzidas em termos racionais posto que os argumentos que as fundamentam não têm abertura epistêmica para tanto (RAZ, I990); (iii) afetos sempre fizeram parte da política, já que os vínculos de pertencimento políticos são tecidos em termos afetivos, e é essa política de pertença que constrói a base para cada comunidade política (GEBHARDT, 2O2I).

Em particular, Mouffe (2005b) chamava a atenção para o "vácuo afetivo" deixado pelo liberalismo democrático em sua aposta por reduzir a dimensão política a decisões técnicoeconômicas, haja vista um suposto consenso em torno de questões normativas substantivas acerca do bem e de como deve ser organizada a vida comum. É nesse vácuo que teriam proliferado os populismos de direita (MOUFFE, 20I4), hábeis na mobilização dos afetos, na apresentação de soluções simplificadoras para problemas sociais e econômicos cada vez mais complexos. Essa abertura foi dada pela crença de que, se as concepções de bem mais 
polêmicas ou irracionais fossem relegadas à esfera do privado, emergiria na esfera pública uma espécie de consenso fundado na razão, cuja única possibilidade de desestabilização seria um ataque pelas forças "irracionais" (MOUFFE, 2000, p. 223).

Esse seria, portanto, um elemento fulcral para a compreensão do debate aqui levantado acerca da participação de argumentos religiosos na esfera pública liberal, na medida em que põe em xeque um de seus pressupostos: o fato do pluralismo. A economia afetiva dos populismos de direita se estrutura em oposição à alteridade e, por conseguinte, à pluralidade de concepções de bem, almejando um retorno a um espaço/tempo idealizado no qual o tecido social seria mais simples e coeso em torno de uma única concepção de bem, de ordem e de família. Sentimentos e afetos foram banidos das conceituações liberais do público, porém os afetos sempre fizeram parte da política, uma vez que todas as políticas de pertencimento são estruturadas em afetos que constroem a base para cada comunidade política. O suposto banimento de afetos dos quadros liberais centrados cria vazios que as políticas étniconacionalistas e racistas exploram para a realização de objetivos políticos. A democracia liberal está, assim, permitindo que diferentes movimentos populistas façam referência a esse vazio por meio de estratégias de emocionalização (GEBHARDT, 202I).

Esse populismo é definido com o auxílio do diálogo com os teóricos da chamada abordagem ideacional a partir de três elementos: a) cosmologia moral maniqueísta; b) visão do povo como totalidade homogênea e virtuosa; e c) definição da elite como corrupta e selvagem (HAWKINS; KALTWASSER, 20I8; MUDDE; KALTWASSER, 20I3, 20I7). Regimes afetivos também são produzidos na democracia liberal, a despeito de seus clamores por objetividade e racionalidade, que geram uma ordem invisível que hierarquiza e marginaliza os saberes daqueles que não se expressam em termos mais passionais (RANCIÈRE, 1999), sendo o populismo de direita uma reação por parte desses grupos. Em especial, esse risco torna-se maior quando a ideia de democracia e de alternância de projetos políticos é minada pela ênfase em impedimentos de origem técnico-econômica que inviabilizariam empreitadas redistributivas sob a alegação de indisciplina fiscal (RANCIÈRE, 1999). A hegemonia neoliberal, ao tentar ceifar na raiz qualquer tipo de contestação, acaba por fragilizar os mecanismos institucionais responsáveis por garanti-la, uma vez que a própria capacidade dos líderes democraticamente eleitos de representar o interesse daqueles que os escolheram passa a ser posta em xeque. Nesse cenário, populismos de direita mobilizam o léxico da soberania popular e dos direitos individuais para levar a cabo projetos políticos que contestam seus fundamentos epistêmicos iluministas.

Em suma, segundo os autores, teria sido em virtude da emergência de um ambiente de fim da política e de que as questões valorativas se tornariam menos relevantes, haja vista um suposto consenso em torno dos princípios morais e econômicos do liberalismo, que se 
criaram as condições de proliferação do populismo de direita (MOUFFE, 200o; RANCIÈRE, I999). Nessa conjuntura, por um lado há os arautos da racionalidade técnico-científica que marginaliza os segmentos da população menos capazes de atender aos requisitos impostos por elites econômicas e sociais cosmopolitas e globalizadas; por outro, aqueles que falam em nome dos oprimidos, reificando alguns de seus atributos identitários. O resultado é a fragilização das instituições e dos próprios princípios que estruturam o liberalismo democrático pela escassez de sujeitos sociais portadores de identidades compatíveis com estes princípios, em um cenário de proliferação de confrontações identitárias entre concepções de bem e valores morais reafirmados como inegociáveis que podem assumir feições nacionalistas, étnicas ou religiosas (MOUFFE, 2000).

No entanto, ao afirmar que os populismos de direita, assim como o tecnicismo neoliberal, por serem estruturados por componentes essencialistas, seriam incompatíveis com uma concepção efetivamente pluralista de democracia (MOUFFE, 2000), os teóricos da democracia radical recuperam o debate Rawls-Habermas em uma terminologia que atualiza os conceitos de doutrina abrangente e abertura cognitiva. Nessa atualização, observa-se novamente a tentativa de hierarquizar concepções de bem cujas participações na esfera pública seriam mais ou menos desejáveis ou disruptivas, deixando novamente os segmentos religiosos em uma situação desfavorável. Afinal, é difícil pensar em uma religião que não se traduza em componentes epistêmicos essencialistas. Mouffe (2000) reconhece que uma sociedade democrática liberal requer a existência de um consenso sobre certo número de instituições básicas, e que o pluralismo radical de fato colocaria em risco as instituições responsáveis por garanti-lo. A diferença é que esses limites não são apresentados como sendo fundados na moralidade ou na racionalidade. Nas palavras da autora: "nenhum estado ou ordem política, nem mesmo liberal, pode existir sem alguma forma de exclusão. Apresentar as instituições da democracia liberal como o resultado da racionalidade deliberativa é reificálas e tornar sua contestação impossível" (p. 227).

\section{Bases do consenso e da hegemonia liberal}

Antes de discutir a crise dessa democracia liberal, é preciso entender as bases que sustentaram esse consenso ou essa hegemonia nas últimas três décadas. Após a Segunda Guerra Mundial, o mundo ocidental estabeleceu certo equilíbrio em torno do chamado welfare state. Por três décadas, entre os anos 1940 e I970, o modelo do Estado de bem-estar social vigorou sem concorrentes em grande parte dos países ocidentais. Eram os anos dourados do capitalismo, na expressão de Hobsbawm (1995). Contudo, a crise do petróleo, em 1973, criou 
obstáculos para o financiamento da política intervencionista do Estado, e esse consenso ruiu. Em seu lugar, assumiu, a partir da década de I980, o neoliberalismo como novo consenso.

É certo que Margaret Thatcher, no Reino Unido, e Ronald Reagan, nos EUA, foram as primeiras grandes experiências nos anos 1980. Mas a mensagem neoliberal se espalhou também pela Europa, com os governos, eleitos em I982, de Helmut Kohl, na Alemanha, e Poul Schlüter, na Dinamarca. Até aqui, todos esses países que aplicaram o modelo neoliberal eram governados por partidos conservadores, da direita do espectro político. No entanto, o que torna a política neoliberal hegemônica a partir desse momento é o fato de até mesmo países governados por partidos social-democratas passarem a aplicar esse modelo. Foi o que ocorreu na década de 1980 em países como França, Portugal, Espanha, Itália e Grécia, governados pelos socialistas François Mitterrand, Mário Soares, Felipe González, Bettino Craxi e Andréas Papandréou, respectivamente(ANDERSON, 1995). Mas foi na década de 1990 que a social-democracia assimilou, não apenas em sua práxis, mas também em seu programa, a economia política do neoliberalismo (WAINWRIGHT, I998). O contexto histórico certamente influiu. O comunismo entrava em colapso, o Muro de Berlim caía em 1989 e a União Soviética chegava ao fim após pouco mais de 70 anos de existência.

Essa mutação pela qual passou a social-democracia na virada da década de I980 para a de 1990 foi bem observada por Anthony Giddens com seu conceito de "terceira via". Para Giddens (200I), o programa social-democrata precisa ser atualizado, pois o mundo pósqueda do muro teria mostrado que não há mais alternativas ao capitalismo. Sob esse registro, Giddens (200I, p. 7) apresenta algumas das causas que levaram ao debate sobre essa atualização programática: "a dissolução do 'consenso do welfare' que dominou os países industrializados até o final da década de 1970, o descrédito final do marxismo e as mudanças muito profundas, econômicas e tecnológicas". Em Giddens (200I), essa atualização programática da social-democracia gera um novo movimento político denominado "terceira via". Trata-se de uma "terceira via" na medida em que esse movimento "é uma tentativa de transcender tanto a social-democracia do velho estilo quanto o neoliberalismo" (p. 36).

Podem ser considerados exemplos de governantes que implementaram a "terceira via" na transição do século XX para o XXI: Bill Clinton, no Partido Democrata (EUA); Tony Blair, no Partido Trabalhista (Reino Unido); Fernando Henrique Cardoso, no Partido da SocialDemocracia Brasileira; Ricardo Lagos, no Partido Socialista do Chile; e Gerhard Schröder, no Partido Social-Democrata alemão. O que une todos eles é a moderação programática em relação à social-democracia do passado e a incorporação da agenda neoliberal em suas políticas econômicas. Em alguns casos, como na Alemanha, partidos supostamente adversários, como a União Democrata-Cristã e o Partido Social-Democrata, conformaram, inclusive, o mesmo governo sob a liderança de Angela Merkel. Assim, os programas dos 
conservadores e dos social-democratas, das direitas e das esquerdas, tornaram-se exageradamente semelhantes.

$\mathrm{Na}$ teoria política, há certa concordância acerca desse processo de uniformização programática dos campos políticos inseridos na democracia liberal, não obstante as mais diversas denominações dadas. Se Giddens definiu esse projeto socialdemocrata de "terceira via", Nancy Fraser (20I7) preferiu conceituar como "neoliberalismo progressista". A ciência política mais recente entendeu esse processo como uma "cartelização" do sistema partidário (MAIR; KATZ, I995). Como bem sustenta Mair (2003, p. 288), "agora se torna cada vez mais difícil os eleitores encontrarem diferenças significativas em termos de ideologia ou de objectivos entre os diferentes partidos". Por outro caminho, trata-se precisamente daquilo que Mouffe (2005a) conceituou como a "pós-política". Independentemente das diferentes denominações, todos concordam que a agenda econômica neoliberal se tonou o consenso da democracia liberal.

\section{Crise do consenso e da hegemonia liberal e a alternativa populista}

Em síntese, em fins do século XX, a democracia liberal construiu um consenso, ou uma hegemonia, capaz de definir qual o pluralismo aceitável em suas sociedades. Para essa democracia liberal, o pluralismo é aceitável até o ponto em que suas instituições políticas e econômicas não sejam rejeitadas na esfera pública. O problema é que ao estreitar as condições sobre o que é ou não é aceitável na esfera pública, a democracia liberal acabou por excluir atores significativos da sociedade civil e política. Por um lado, os atores subalternos - numa linguagem gramsciana - que contestam as instituições econômicas liberais buscaram organizar certo populismo de esquerda para furar a bolha da estreita esfera pública liberal. Nesse populismo de esquerda pode-se encontrar o Podemos, na Espanha; a França Insubmissa, na França; Bernie Sanders, nos Estados Unidos; e Jeremy Corbyn, no Reino Unido, entre tantos outros preocupados em estabelecer uma crítica ao consenso neoliberal (RODRIGUES, 20I8; RODRIGUES; FERREIRA, 2020). Por outro lado, o mesmo movimento foi feito pelo populismo de direita, embora preocupado não com a crítica da economia neoliberal, mas sim com as instituições políticas liberais consideradas demasiadamente progressistas. Assim, entrou em crise a hegemonia da democracia liberal no início do século XXI.

Um caso particular desse populismo de direita é a oposição à agenda do reconhecimento bem específica desse início do século XXI - afirmação de identidades de gênero, raça, sexualidade etc. Movimentos reacionários excluídos da esfera pública, muitos deles religiosos, organizaram certo populismo de direita capaz de articular demandas sociais racistas, machistas e homofóbicas em torno de um mesmo projeto político. Donald Trump (EUA), Marine Le Pen (França) e Jair Bolsonaro (Brasil) são expressões desse tipo de 
articulação populista. O que caracteriza esse populismo de direita é justamente o casamento dessa agenda reacionária nos valores, com a agenda econômica neoliberal predominante na democracia liberal.

A aproximação dos cristãos com o discurso neoliberal não é exatamente intuitiva. Historicamente, a democracia cristã construiu no cenário internacional um discurso conservador nos costumes, mas sem abominar a participação do Estado na economia. No Brasil não foi diferente. Na década de 1960, o programa do Partido Democrata Cristão (PDC) sustentava que "em oposição ao capitalismo, que nega a justiça, e ao comunismo, que esmaga a liberdade, a democracia cristã luta pela instauração de uma ordem social que realize a justiça sem destruir a liberdade" (CHACON, I98I, p. 47I). É bem verdade que não se tratava da defesa de um intervencionismo econômico do Estado, mas sim da proposição de políticas sociais e trabalhistas (WERNECK VIANNA, I98I). Mas, ainda assim, algo bem diferente do que propõe o discurso neoliberal.

Como se sabe, a democracia cristã foi um movimento político internacional que reuniu em boa convivência atores políticos católicos e protestantes. No início do século XXI, entretanto, uma parte considerável do campo evangélico rompeu com essa ideologia tradicional da democracia cristã. Evangélicos mantiveram os valores conservadores nos costumes, mas na economia assimilaram o programa do neoliberalismo. Numa linguagem tipicamente cristã, realizaram um aggiornamento neoliberal.

Bom que se diga, a democracia cristã não foi a única que passou por essa metamorfose. Como já mencionado, a própria social-democracia, na década de 1990, passou pelo mesmo processo com a construção daquilo que Giddens (200I) chamou de "terceira via". Curiosamente, a própria democracia cristã se apresentava no século XX como uma "terceira via" entre o liberalismo e o marxismo (CHACON, 198I; COELHO, 2003). Nancy Fraser (2017), em período mais recente, preferiu denominar criticamente - ou ironicamente, se preferir essa nova agenda social-democrata como um "neoliberalismo progressista". Fraser foi além e demonstrou como, em oposição ao "neoliberalismo progressista", emergiu com força nos últimos anos certo "neoliberalismo reacionário". Seriam então os partidos evangélicos do século XXI no Brasil os representantes de um "neoliberalismo reacionário"?

Embora não trate exatamente desse processo, Wendy Brown talvez seja a autora que melhor interpretou a dinâmica neoliberal que informou indiretamente essa transformação programática. O argumento de Brown (2019) é o de que não se trata de um encontro, de uma complementariedade ou de uma convergência entre duas racionalidades distintas, a conservadora e a neoliberal. Trata-se de uma mesma racionalidade, em que a moralidade tradicional deve ser entendida dentro da razão neoliberal. A literatura especializada, diz Brown, buscou entender a relação entre a moral conservadora e a política neoliberal como 
complementar, híbrida, ressonante, convergente e de exploração mútua. Para Melinda Cooper, por exemplo, conservadores e neoliberais concordam, por motivos distintos, que os valores familiares deveriam ser encorajados. Essa seria uma explicação da convergência. Para os conservadores, a razão para essa valorização familiar é moral. Para os neoliberais, a razão é econômica. O que importa é que as duas racionalidades convergem em uma mesma direção: a substituição do Estado de bem-estar social pelas "obrigações naturais" e pelo “altruísmo" da família (COOPER, 2017). Outros autores preferem uma explicação mais cínica sobre um processo de exploração mútua. Tradicionalistas cristãos teriam aceitado a agenda neoliberal em troca do apoio empresarial para a agenda conservadora (MACLEAN, 2OI7).

Como já dito, Brown discorda dessas interpretações. A autora argumenta que na própria obra de Friedrich Hayek, um dos principais nomes da teoria neoliberal, "o mercado e a moral, igualmente importantes para uma civilização próspera, estão enraizados em uma ontologia comum de ordens espontaneamente evoluídas carregadas pela tradição" (BROWN, 20I9, p. II8). Há, portanto, uma simetria ontológica estabelecida por Hayek entre os códigos morais e as regras do mercado. Essas duas práticas evoluíram ao longo do tempo a partir das tradições em uma conformidade voluntária sem a coerção do Estado. Cabe ao Estado apenas a proteção dessas tradições por meio de leis sobre propriedade, casamento, herança etc. Por essa razão, dirá Brown (2019, p. I3I), Hayek entende que "o maior erro da social-democracia jaz em sua tentativa de substituir uma ordem espontânea evoluída historicamente, suportada pela tradição e instalada no costume, por projetos racionais mestres para a sociedade".

Essa descrição do sonho de Hayek não é apenas teórica. No neoliberalismo realmente existente, essa racionalidade neoliberal também se efetivou. Sob esse registro, vale lembrar de Margareth Thatcher e do início da implementação da sua agenda neoliberal no Reino Unido. Ao lado da privatização econômica levada adiante por seu governo, também avançava uma "privatização por meio da familiarização e da cristianização" (BROWN, 20I9, p. I4I). A famosa frase de Thatcher de que não existe sociedade, mas sim indivíduos e suas famílias, é certamente sintomática desse neoliberalismo. Mas esse neoliberalismo efetivou apenas parcialmente o sonho de Hayek. Diferentemente da utopia hayekiana de uma sociedade de instituições políticas isoladas dos interesses, ao mesmo tempo que promovem a competição, no neoliberalismo realmente existente, os Estados foram dominados pelas finanças e por indústrias poderosas que buscam legislação e ação estatal em prol de seus interesses (BROWN, 2019).

Embora esse processo remonte à década de 1980, nos últimos anos houve uma intensificação dessa agenda no programa evangélico. Como bem aponta Brown (2019, p. I35), "reivindicações de liberdade têm sido o cerne da estratégia da direita religiosa para recristianizar a esfera pública desde os anos 1990, mas foram intensificadas e popularizadas 
na década passada". A autora está olhando para os Estados Unidos, em particular para o governo de Donald Trump, mas sua avaliação pode facilmente ser generalizada para o cenário internacional. Brown menciona, inclusive, a campanha de Marine Le Pen, na França, como exemplar desse processo. Não cita, contudo, o caso brasileiro, afinal, o livro foi concluído antes da eleição de Bolsonaro, em 20I8. Mas não é difícil fazer uma analogia entre o caso brasileiro, o francês e o estadunidense.

Se Brown (2019) está correta, então a ideia de um "neoliberalismo conservador" é uma redundância. Mas talvez, nos últimos anos, não seja apenas um "neoliberalismo conservador" que esteja em ascensão. Pode ser que no período mais recente o mundo esteja convivendo com a existência de um radicalismo, ou melhor, de um extremismo entre os tradicionais conservadores. Se isso é verdade, então faz sentido o uso que Fraser (2017) faz da noção de "neoliberalismo reacionário" ou mesmo de "neoliberalismo hiper-reacionário" para descrever os movimentos contemporâneos da direita no cenário internacional, em particular de Trump, nos Estados Unidos.

\section{Considerações finais}

Em síntese, a democracia liberal buscou construir, nos últimos 40 , anos certo consenso ou melhor, certa hegemonia baseada no neoliberalismo. A democracia liberal sempre se apresentou plural em seu discurso público, mas, como visto, esse pluralismo liberal tem seus limites. E esse limite foi a preservação da agenda neoliberal. Contudo, nesse processo emergiu certa contradição que direcionou a democracia liberal para uma crise. Ao transitar, na década de 1990, para a "terceira via" ou para um "neoliberalismo progressista", a democracia liberal entrou em contradição com a própria gênese conservadora do neoliberalismo, como aponta Brown (2019). Insatisfeitos com esse processo, líderes políticos, muitas vezes orientados por valores evangélicos, organizaram contra esse aggiornamento da democracia liberal um populismo de direita. Excluídos daquele consenso da "terceira via" com o qual nunca concordaram, esses populistas de direita atacaram a democracia liberal em nome do retorno às origens de um projeto neoliberal e conservador inacabado. Articularam demandas xenófobas, racistas, machistas e sexistas com a defesa de um Estado mínimo. E, em nome desse projeto, ridicularizaram as velhas instituições da democracia liberal.

O fato de amplas parcelas da população terem aceitado essa crítica do populismo de direita tão facilmente revela como esse projeto da democracia liberal nunca foi um consenso legítimo nas sociedades, mas sim fabricado artificialmente top-down. Mas isso não significa dizer que essas amplas parcelas sociais concordem plenamente com toda a crítica organizada pelo populismo de direita. Talvez - e mais do que uma hipótese, trata-se de uma aposta -, o 
que essas amplas parcelas da sociedade aguardam é por um ator político que organize a crítica dessa democracia liberal sem o conteúdo reacionário do populismo de direita. Um ator que articule em um único projeto político todas as demandas sociais críticas do próprio consenso neoliberal - o que talvez esperem é pela chegada de um ator portador de um projeto de democracia radical.

\section{Referências}

ALVES, A. R. C. O conceito de hegemonia: de Gramsci a Laclau e Mouffe. Lua Nova:Revista de Cultura e Política, n. 80, p. 7I-96, 2010.

ANDERSON, P. Balanço do neoliberalismo. In: SADER, E.; GENTILI, P.(Orgs.). Pós-neoliberalismo: as políticas sociais e o Estado democrático. Rio de Janeiro: Paz e Terra, I995. p. 9-23.

BROWN, W. Nas ruínas do neoliberalismo: a ascensão da política antidemocrática no Ocidente. São Paulo: Politeia, 2019.

CHACON, V. História dos partidos brasileiros. Brasília: Editora UNB, I98I.

COELHO, S. A. O Partido Democrata Cristão: teores programáticos da terceira via brasileira (19451964). Revista Brasileira de História, v. 23, n. 46, p. 20I-228, 2003.

COOPER, M. Family values: between neoliberalism and the new social conservatism. New York: Zone Books, 2017.

ESTLUND, D. The insularity of the reasonable: why political liberalism must admit the truth. Ethics, n. 108, p. 265, jan. 1998.

FRASER, N. From progressive neoliberalism to trump - and beyond. American Affairs, v. I, n. 4, 2017.

GARDBAUM, S. Liberalism, autonomy, and moral conflict. Stanford Law Review, v. 48, n. 2, p. 388, jan. 1996.

GEBHARDT, $M$. The populist moment: affective orders, protest, and politics of belonging. Distinktion:Journal of Social Theory, v. 22, n. 2, p. 129-151, 2021.

GIDDENS, A. A terceira via: reflexões sobre o impasse político atual e o futuro da social-democracia. Rio de Janeiro: Record, 200I.

GREENAWALT, K. On public reason. Chicago-Kent Law Review, n. 69, p. 688, 1993.

HABERMAS, J. Direito e democracia: entre facticidade e validade. Rio de Janeiro: Tempo Brasileiro, 2003.

HABERMAS, J. Fée saber. São Paulo: Editora Unesp, 2013.

HAWKINS, K.; KALTWASSER, C. R. The ideational approach to populism. Abingdon: Routledge, 2018. 
HOBSBAWM, E. Era dos extremos: o breve século XX (19I4-I99I). São Paulo: Companhia das Letras, 1995.

LACLAU, E.; MOUFFE, C. Hegemonia e estratégia socialista: por uma política democrática radical. São Paulo: Intermeios, 2015.

MACLEAN, N. Democracy in chains: the deep history of the radical right's stealth plan for America. New York: Viking, 2017.

MAIR, P.; KATZ, R. Changing models of party organization and party democracy: the emergence of the cartel party. Party Politics, v. I, n. I, p. 5-28, 1995.

MAIR, P. Os partidos políticos e a democracia. Análise Social, v. 38, n. 167, p. 277-293, 2003.

MOUFFE, C. For a left populism. London: Verso, 2018.

MOUFFE, C. On the political. Abingdon: Routledge, 2005a.

MOUFFE, C. Politics and passions. Ethical Perspectives, v. 7, n. 2, 2000.

MOUFFE, C. Populism is a necessity. The European, jan. 15 20I4. Disponível em: $<$ http://en.theeuropean. eu/chantal-mouffe-3/7859-fighting-right-wing-populism-ineurope >. Acesso em: 2 I mar. 2018.

MOUFFE, C. The limits of John Rawls's pluralism. Politics, Philosophy \& Economics, v. 4, n. 2, p. 22 I23I, $2005 b$.

MOUNK, Y. O povo contra a democracia. São Paulo: Companhia das Letras, 2019.

MUDDE, C.; KALTWASSER, C. R. Populism. In: FREEDEN, M.; STEARS, M.; SARGENT, L. T. The Oxford Handbook of Political Ideologies. Oxford: Oxford University Press, 20I3. p. 493-5I2.

MUDDE, C.; KALTWASSER, C. R. Populism: a very short introduction. Nova York: Oxford University Press, 2017.

MURPHY, A. Rawls the Shrinking Liberty of Conscience. The Review of Politics, v. 60, n. 2, p. 269-76, 1998.

PERRY, M. J. Morality, politics, and law: a bicentennial essay. Nova York: Oxford University Press, 1988.

RANCIÈRE, J. Disagreement: politics and philosophy. Minneapolis: University of Minnesota Press, I999.

RAWLS, J. Justice as fairness: a restatement. Cambridge: Harvard University Press, 200I.

RAWLS, J. Oliberalismo político. São Paulo: Martins Fontes, 2OII.

RAWLS, J.; HABERMAS, J. Debate sobre el liberalismo político. Barcelona: Ediciones Paidos, 1998.

RAZ, J. Facing diversity: the case of epistemic abstinence. Philosophy \& Public Affairs, p. 3-46, I99o. 
RODRIGUES, T. Populismo de esquerda versus populismo de direita no início do século XXI: o conflito político nos EUA, Inglaterra, França e Alemanha. Revista Estudos Políticos, Niterói, v. 9, n. 17, p. $70-85,2018$.

RODRIGUES, T.; FERREIRA, D. Estratégias digitais dos populismos de esquerda e de direita: Brasil e Espanha em perspectiva comparada. Trabalhos em Linguística Aplicada, v. 59, n. 2, p. IO70IO86, 2020.

SCHMITT, C. O conceito do político. Teoria do partisan. Belo Horizonte: Del Rey, 2008.

SILVA, M. G.; RODRIGUES, T. O populismo de direita no Brasil: neoliberalismo e autoritarismo no governo Bolsonaro. Mediações - Revista de Ciências Sociais, v. 26, p. 86-IO7, $2 \mathrm{O} 2 \mathrm{I}$.

WAINWRIGHT, H. Uma resposta ao neoliberalismo: argumentos para uma nova esquerda. Rio de Janeiro: Zahar, I998.

WERNECK VIANNA, L. O sistema partidário e o Partido Democrata Cristão. In: FLEISCHER, D. (Org.). Os partidos políticos no Brasil. Brasília: Editora UnB, I98I.

YATES, M. Rawls and Habermas on religion in the public sphere. Philosophy \& Social Criticism, v. 33, n. 7, p. 880-89I, 2007.

YOUNG, I. M. Representação política, identidade e minorias. Lua Nova: Revista de Cultura e Política, $\mathrm{n}$. 67, p. I39-190, 2006. 